\title{
THE ACHIEVEMENT OF PAUL BARAN
}

\author{
BY HARRY MAGDOFF
}

A New Deal economist, responsible during the war for planning and controls in key manufacturing industries, Harry Magdoff was later in charge of the Department of Commerce monthly, Survey of Current Business, and Special Assistant to the Secretary of Commerce. He is the author of Production, Employment, and Productivity in 59 Manufacturing Industries, and lecturer in economics at the New School for Social Research.

Paul Baran was a social scientist and a Marxist. While economics was his major field of study, his interest in economics and his approach to the study of economic developments were part and parcel of his continuous search for a better understanding of human society: to find out how it operates and how it can be changed for the benefit of man. He found in Marx's studies and thought the most satisfactory explanation of how and why societies change, of the origin and development of capitalist society, and of the transformation of capitalist to socialist society.

Baran surely knew as much about Marx's writings as any "Marx specialist." But he did not use this knowledge to become a mere commentator on or interpreter of Marx. Nor did he in his studies of contemporary society seek to fit the facts into a preconceived Marxist mold. Instead he adopted Marx's way of thinking: he virtually breathed Marxism. Not only did he absorb Marx's analyses, but he learned from Marx how to ask the important questions and how to seek out the significant relationships among the infinitude of economic and social phenomena. Confronted with changes in monopoly capitalism, in imperialism, and in the construction of socialism, he did not hunt up and rely on the appropriate quotation. Instead, he asked: how would a Marx tackle this problem? This meant persistent grappling and struggle with new facts and new theories to discover the significant and the relevant. It also meant a continuous re-examination of Marx's hypotheses in the light of new. facts and developments.

Baran brought to his studies not only brilliance and a rest- 
less curiosity, but a well-trained and well-equipped mind. The fortunes of life led him to explore and learn from three different cultures-Russian, German, and Anglo-American. In Baran. these cultures blended well, and they enriched his knowledg( and analytical competence.

Above all, Baran was a man of passion-passionate in the search for truth and about the uses to which this truth could bc put. It was not truth in and of itself he wanted, but knowledge: and understanding that would help eliminate poverty and other social ills. His credo was forcefully stated in "The Commitment of the Intellectual" (MONTHLY REview, May 1961, reprinted above beginning on page 1 ). In his own words:

The desire to tell the truth is therefore only one condition for being an intellectual. The other is courage, readiness to carry on rational inquiry to wherever it may lead, to undertake ruthless criticism of everything that exists, ruthless in the sense that the criticism will not shrink either from its own conclusions or from conflict wtih the powers that be (Marx). An intellectual is thus in essence a social critic, a person whose concern is to identify, to analyze, and in this way to help overcome the obstacles barring the way to the attainment of a better, more humane, and more rational social order.

The article from which this quotation is taken is itself illustrative of Baran's commitment. For this was not an article requested by the MONTHLY REview editors, and obviously, it was not one designed to enhance his professional prestige. He felt he had to write this article just as he had to cry out against the invasion of Cuba and against all the evils of imperialism: it was his responsibility as a student and a citizen. He was deeply troubled by the apathy and indifference of his fellow social scientists, and he wholeheartedly accepted the dictum of Goethe that "one must from time to time repeat what one believes in, proclaim what one agrees with and what one condemns." * Therefore, he had to speak his mind. Accepting Marx's thesis, "The Philosophers have only interpreted the world in various ways; the point, however, is to change it," he, in effect, insisted that by neglecting the need to change the

* See his letter from Moscow of August 29, 1957, quoted above, p. 55 . 
world, social scientists in the United States have become false and impotent interpreters.

Passion and objectivity, by currently accepted standards, are considered to be mutually exclusive in the social sciences. It is conceded that a good general should and can, at one and the same time, be a man of passion and a cool-headed realist. But not the social scientist: he apparently cannot be trusted to recognize and respect the truth if he feels too strongly about it. Obviously, passion can interfere with objectivity, but it is equally true that the mere appearance of objectivity can serve to becloud the truth. Excessive interest in appearing to be objective can lead to ignoring the implicit assumptions about the permanence of the institutions studied and consequently to an unquestioning acceptance of the myths that have grown up in the process of attempting to guarantee this permanence. It can also lead to the restriction of studies to safe, if relatively insignificant, areas-those about which controversy can be conducted in gentlemanly fashion.

A man like Baran could not accept passion and truth as mutually exclusive. Real objectivity, to him, meant facing up to the conflict between passion and the comprehension of reality. He understood that the influence of one upon the other and the struggle between the two were part of the process of the endless search for objective truth. Struggle was not alien to him. He saw himself as a fighter in all his activities: a fighter for knowledge, for the defeat of irrationality, for the progress of man.

\section{The Quality of Baran's Thought}

The paths to knowledge and discovery are diverse. Explorers choose their routes in different ways, influenced by teachers, environment, and their own personalities. If one wishes to understand and appreciate an original thinker, it is not sufficient merely to classify him as, say, a Marxist. More important is what he selects from Marx for his own use and how he uses these aspects of Marx's thought.

While Baran appreciated the formal procedures of the typical academic study of economics and even enjoyed the aesthetics of mathematical reasoning, he did not pursue these lines of inquiry because in the main they do not lead to further 
understanding of the important issues of capitalist society and are too often a way to avoid the issues. Perfecting even such important tools of modern analysis as input-output and linear programming could contribute to greater efficiency of a planned economy, but would have little importance in transforming an irrational society into a rational one. To summarize his own program of studies, Baran chose this apt quotation from J. D. Bernal as the epigraph of his magnum opus, The Political Economy of Growth: "What social science needs is less elaborate techniques and more courage to tackle, rather than dodge, the central issues. But to demand that is to ignore the social reasons that have made social science what it is."

Baran's way toward better understanding of the central issues was to search for synthesis, for a unifying approach to the diverse trends in economics, politics, social problems, and culture. This is not to say that he expected to find a simple, allembracing formula that would explain all of the different social and cultural phenomena. That would border on mysticism. The never-ending approach to synthesis meant for Baran that each phase of society was to be studied not as an isolate but in terms of how it is influenced by and in turn influences the rest of society. This does not mean providing a long list of all the possible interconnections, causal or temporal. It does mean trying to find those significant interrelationships which explain how the phenomena arise and disappear, and how they behave (or operate) in the environment in which they appear. From such study of the concrete in its own environment comes the ability to find the common elements, and therefore the generalizations, which lead to useful syntheses. But the process does not end there. For the syntheses must then be used to re-examine the concrete interrelations, both as a test of the generalizations and to anticipate new developments in society.

This approach is very different from the customary scholarly practices of our times. The separation of the disciplines, together with prevailing methods of education and training, inhibit even the more courageous thinkers. Since all the disciplines evolve according to their own rules, there is a tendency, greatly reinforced by bureaucratic impulses, for each in its isolation to become purer and more abstract. When the practitioners begin 
to feel uncomfortable because of the apparent sterility of their results, or when confronted with a too-obvious disparity between theory and reality, they begin to look elsewhere for new ideas. At such moments, the economists seek new insights from the sociologists, the sociologists from the political scientists, etc.; and usually a little amateur psychoanalysis is thrown in for grood measure. But by this time it is too late. The old definitions and the habitual ways of thinking, arrived at in all their isolated purity, are encrusted. The addition of so-called new variables does not make for synthesis; it merely results in an eclectic jumble of ideas.

The strategic aspect of Baran's thought, following Marx's example, was to distinguish capitalist society from past and future societies and thus to study it as a developing organism. Instead of the mere addition of history and sociology to economics as in a cookbook recipe, examination of capitalism as a social system sui generis makes possible meaningful distinctions between attributes common to all societies and those unique to the capitalist system. This way of thinking provides the framework for examining concretely the interrelations of the different parts and enables the student to arrive at unifying principles to mark off different stages in capitalist society as it develops and changes.

This approach also implies a critical view. The analyst must search not only for the origins and effective causes of the growth of the system and its institutions, but also for the sources of its decline and transformation. To understand development and change one has persistently to look for the negative and understand the interaction and struggle between the negative and the positive, between the forces tending to preserve the status quo and the forces making for change. The role of critic suited Baran well. His contempt for complacency, his acute sense of irony, and his hatred of sham and irrationality added zest to his critical analysis of society. He was, however, a critic in the best sense of the term. Because the purpose of the criticism was a ruthless search for the truth, he looked for whatever could help in arriving at the truth. All new developments therefore had to be examined, all new ideas and theories had to be understood and evaluated. By the same token, pre- 
vailing myths and illusions parading under the banner of social science had to be exposed and fought. But this attack was to pave the way for a better understanding of reality. He was a critic of capitalist society, but, as with Marx, this was part of the movement toward a better society.

If Baran had a faith, it was his unshakable confidence in the ability of man to reason and to use his reason for human progress. Had he believed in Satan, his devil would have been irrationality. But objective reason, to Baran, was not God-given or independent of man: it was a product of man, anchored in man's expanding and deepening understanding of nature and society. Thus the pursuit of reason was the concrete exploration and practical exploitation of the natural and social conditions of progress. The irrationality to be fought was not only superstition and mysticism but the lack of faith in objective reason itself and in the ability of man to use it to improve his lot.

\section{The Failures of Bourgeois Economics}

The bourgeois economists' lack of faith in the objective reason of man was at the heart of Baran's quarrels with his colleagues. For the economists in their search for the rationale of a market economy come to believe that only through the market can an economy operate rationally. Just as in religion, to paraphrase Marx, the product of man's mind is personified in a God and set of rules that govern man's destiny, so does the anarchy of the market as conceived in the minds of economists become for them the true objective reason.* The faults economists find with economic affairs are attributed to interferences with the market by monopolies, by strong unions, by perverse governments. And those economists who are bold enough to question the all-embracing wisdom of the market, the agnostics, confine their remedies to political tinkering with the market.

The academic economists have not been able to accept

* The powerful influence of these ideological preconceptions can be witnessed in the "opened-up" debate on economic issues in socialist countries. A frequent reaction to the distortions and abuses of central planning is the uncritical worship of the holy market as a cure-all. 
Marx's critique of the fetishism of commodities or the conclusions that follow from it: the market is not the highest form of man's wisdom or a necessity of nature but a product and reflection of man-made social forces; the rationality of the market is that it is a rational medium for the operation of the institutions of capitalism, and it functions in such a fashion as to reproduce the social and economic relations of capitalism. Unable to recognize the nature of this connection between the market and social forces, bourgeois economists are equally unable to understand the limitations of their own analyses. The body of thought which appears to them to demonstrate the "rationality" of the market is in reality constructed of axioms and definitions which in effect assume the conclusions- sometimes explicitly, but more often implicitly by their treatment of economic phenomena in isolation and independent of their historic development.

As a result of these limitations, the academic economist is ill-equipped for objective study of the irrationality of the market economy as evidenced in such phenomena as persistent unemployment, poverty, super-exploitation of the Negro, waste, and stagnation. He is particularly at a loss when it comes to penetrating the relationship between the stagnation of the underdeveloped areas and the functioning of the advanced industrial nations. Especially alien to his way of thinking is the concept of the backward nations as an integral part of the market system of the advanced nations, the idea that the "rational" world markets and their institutions operate in such a fashion as to reproduce continuously the backwardness and economic dependency of the underdeveloped nations.

Bourgeois economic theory, in other words, is by its very nature incapable of explaining why capitalism induces rapid development of productive resources in a relatively small part of the world capitalist system and acts to restrict the growth of productivity in the rest of the capitalist world. Modern economic theory (after Ricardo and John Stuart Mill) grew and flourished by directing its attention to mechanical aspects of a market in equilibrium and how the market achieves equilibrium. The underlying questions asked by economists concerned the static aspects of an intrinsically harmonious system. The way of 
thought that evolved within the confining limits of static equilibrium study continue to dominate these economists' analyses when they alter their models and equations to try to explain dynamic changes over time. Even the Keynesian "revolution," although it incorporated a theoretical analysis of business fluctuations within the main body of economic thought, did not break through the limitations imposed by concentrating on the short-run and avoiding the issues of secular growth and decline.

In recent years-starting just before the war, but especially in the postwar period-more and more economists have begun to explore the question of economic development. New tools had to be developed for this study, and interestingly enough they turned out to be either independent rediscoveries of Marx's tools or directly derived from Marx. But what is important about tools is how they are used, and it must unfortunately be said that these excursions into dynamic analysis, despite their formal affinity to Marxian thought, are usually quite sterile. The reason is that this dynamic analysis, although more and more mathematically refined, has all the weaknesses of the abstract, unhistoric method of traditional economic theory. Modern growth theory does not critically examine the fundamental assumptions of traditional economics to find out where it has gone wrong; the new theory is for the most part merely an appendage of the old.

The absence of a vital theory shows up clearly in the numerous studies of retardation of growth in underdeveloped countries. These studies are often excellent contributions to a descriptive examination of the various problems facing these societies. But their competence is usually restricted to the recital and documentation of a long bill of particulars of ills and evils. Attempts at diagnosis usually lead to concentration on one or two symptoms of the disease. Population is growing too rapidly, or the amount of capital is insufficient, or there are too few daring entrepreneurs. The proposed remedies, flowing from a superficial diagnosis, are necessarily concerned with symptoms rather than causes. It is not surprising that the frustrations produced by the contrast between theory and reality open the road to non-economic explanations. Dragged in, for example, 
are anthropological concepts of the incompatibility of value systems of different cultures, or psychological "explanations" of when and where dynamic elites (a fancy term for Westernstyle capitalists) have attained high social status.

Finally, the poverty of traditional economics, especially when it deals with development, results from the main taboos of the profession: against the use of socialist economic planning to develop productive resources and against analysis of the role of imperialism as an instrument in maintaining the backwardness of underdeveloped countries. In these respects, the situation today is, with the rarest of exceptions, as described by Veblen in The Higher Learning In America where he pointed out that the social scientists "are free to give the fullest expression to any conclusions or convictions to which their inquiries may carry them. That they are able to do so is a fortunate circumstance, due to the fact that their intellectual horizon is bounded by the same limits of commonplace insight and preconceptions as are the prevailing opinions of the conservative middle class."

These preconceptions are reflected in the worship of the rationality of the market place and the related inability to comprehend social revolutions which, through changing the class in control of economic and social power, take over the direction of the economy to achieve clearly defined goals. After all, how does one know whether such goals are rational if there is no free market by which to judge them? The economists are disturbed by the disruption of customary markets and the inevitable inefficiencies accompanying a revolution such as Cuba's, but they do not weigh these negative aspects against the fact that for the first time all Cuban children get first priority on a minimum amount of milk, or that at long last illiteracy is overcome. They hail the successes signalized by the rapid growth rate of the Mexican economy but do not recognize that this growth involves an allocation of economic resources such that 24 percent of the population over one year of age never eat meat, fish, milk, or eggs.*

This is not to say that academics as individuals do not

* Annuario Estadistico de los Estados Unidos Mexicanos, 1960-1961, Mexico, D.F., 1963, p. 30. 
sympathize with suffering, or are not aware of it. But their task, as "scientists," is to explain the existing social system and help to make it work better. Socialist economic planning is simply not on the agenda as an alternative to the reforms they propose. And here, as the case of imperialism vividly shows, national interest raises its head. An excellent illustration of the taboo against analyzing imperialism is the experience Paul Baran had in placing his path-breaking article, "On the Political Economy of Backwardness." It took some two years and numerous rejection letters before a publisher could be found for this forceful and brilliant statement of the thesis later expanded in The Political Economy of Growth. Two of the rejection letters belong side by side in a textbook on imperialism. One is from a world-famous British economist who explains most politely that despite the many virtues of the article, he could not very well accept it for publication since the model Baran draws of an underdeveloped country is much too general. Surely, Baran's description of the way imperialism works does not properly apply to present and former British colonies. Perhaps Baran's article would be closer to the truth if he restricted his model to Latin America. The rejection letter from a United States economist complained that while the study might be a useful review of backwardness and imperialism in the rest of the world, it surely didn't apply to Latin America, where progressive reforms were under way.

The article finally found a home in the relatively obscure Manchester School of Economics and Social Studies, January 1952. It caused a notable stir in the colonial world, including Latin America and the British sphere, where the generalized descriptions of the nature and causes of backwardness were immediately recognized and identified.

The reception given to this article was merely a foretoken of the excitement aroused in underdeveloped countries by Baran's Political Economy of Growth. Here, finally, was a fulldress analysis which could clear the way for developing specific programs to transform stagnant and backward economies. No one realized more clearly than Baran himself that his work was not the final word and that much more study and research was needed. But his forthright analysis provides the framework and 
inspiration for further work along the avenues he opened up. It also serves as a textbook to educate those who are going to do the transforming, and as a useful guide to the tasks which must be undertaken. Copies of this book on the shelves of the leaders of the Cuban Revolution are well thumbed and heavily underlined. Just as it is an unusual sight to see a copy of the book in United States bookshops, it is a rare bookstore in Mexico City, for example, which does not prominently display a copy of the Spanish edition.

\section{The Marxist Contribution}

The vitality and significance of The Political Economy of Growth stems from the fact that it is rooted in the Marxist way of thought. For the Marxist body of economic and social analysis provides the most effective apparatus for understanding the problems of economic development. Marx's thought is directed to precisely the problems of growth, class conflict, social change, and transformation of societies; and these are the immediate problems of the underdeveloped world. Moreover, the method of analysis he used in studying society as a developing organism and the differences produced by historic change provides the economist with tools specially designed to penetrate the complexity of the underdeveloped societies, to lay bare in Baran's term, the "morphology of backwardness." (It is difficult to refrain from pointing out, in passing, the paradox that it is Marx, the critic, who provides the more effective instruments for studying growth, because he paid so much attention to capital accumulation-in terms of its historical origin and as the driving force of capitalism. The scientists of the status quo on the other hand, offer little help and frequently mislead because their mental energies have been focussed on equilibrium or, at best, the mechanics of the business cycle.)

While Marx's work provided the key, some of the concepts and ways of thought that later grew up in the Marxist environment had first to be cleared away. One of the main obstacles to constructive analysis in this area was the acceptance, implicit or explicit, of a rigid framework of economic stages of social development. Since Western Europe went through a stage of feudalism before the stage of capitalism, and the stage of 
capitalism was to be the precursor of socialism, it was assumed by many followers of Marx that this progression was a necessary law of social development. It may be belaboring the obvious to emphasize here that such a concept is alien to scientific and, by the same token, to Marx's thinking. The hallmark of Marx's approach is the discovery of general truths about the specific changes that took place in the geographic areas and time periods he investigated, based on the evidence which was then available. From this, Marx distilled what he discovered to be the necessary interrelations-distinguishing between the primary and secondary elements--which explained the historical transformations of human societies. Acceptance of these generalizations as the most fruitful guide to explorations into questions of history and social science does not mean acceptance of a supra-historical design for all peoples, regardless of specific historical developments. Such acceptance would be mysticism, not science.

The search for a rigid, evolutionary, and "Marxist" pattern of social change induced an overemphasis on the feudalor seemingly feudal-features of underdeveloped, colonial societies. The special stress on feudalism was based not so much on a critical examination of that form of society and the specific aspects of land relations but, quite frequently, on the preconceptions of the investigator and the superficial similarities between features of the country investigated and those of classic feudalism (usually an idealized representation of what feudalism was supposed to have been).* There was then superimposed upon this rigid pattern of development the role of imperialism in entrenching these seemingly feudal features. From this it was deduced that the middle classes were being prevented from breaking out of the feudal fetters because of the protection afforded the latter by political and economic imperialism. Hence there was bound to be a temporary identity of interests in the struggle for national independence between the oppressed masses and those members of the bourgeoisie who are nationalistic in

*The existence of certain types of dependent economic relations based on privilege is not sufficient evidence to characterize a feudal or semifeudal society, nor did the existence of slavery in the United States make the latter-or even the southern region of the United States-a slave society. Slavery in the United States was in effect a special feature of United States capitalism. 
spirit and, in addition, want to eliminate the protectors of the feudalistic restrictions on the growth of industrial capitalism. The time elapsing between the transition from feudalism to capitalism and the transition from capitalism to socialism might be relatively short, but a two-stage evolution along these lines was the most reasonable pattern to expect.

Implied in this viewpoint are several assumptions: (1) Important sections of the bourgeoisie will not only support the fight for political independence but will also support the measures needed for economic independence from imperialism. (2) Economic independence can be achieved without disrupting (or destroying) the trade channels, financial institutions, and market relations (including the price-and-profit structure) on which the "independence-striving" bourgeoisie depend for their prosperity. (3) After imperialist domination and feudal fetters are removed, the national bourgeoisie can achieve fairly rapid industrialization, under today's conditions, without the assistance of state-protected monopolies which would act as fetters on the competition needed for the spread of industrialization. And (4) the fetters of feudalism-imperialism can either be removed without the revolutionary participation of the oppressed classes; or if these classes do participate, they will carry out the revolution without insisting on additional goals inimical to the interests of the industrializing bourgeoisie.

The above characterization of the "rigid" Marxist analysis and its implications has been deliberately exaggerated in an attempt to clarify the value of Baran's contribution. In fact, Baran, in my opinion, was influenced by some of these preconceptions and did not make a complete breakthrough. But his independence of thought, intensive study, and talent for synthesis enabled him to present an extremely valuable extension of the analysis of imperialism, one which is a closer approach to reality, and, as indicated above, points the way to more realistic study and the development of more effective programs.

\section{Baran's Analysis of Underdevelopment}

The present examination of Baran's contribution to economic and social thought is focused on his analysis of under- 
development. He has given us light and wisdom in other fields as well. The bulk of his work in other fields, including the part in his Political Economy of Growth not discussed here, is concerned with the analysis of monopoly capitalism in the United States. His work on this subject will no doubt appear in a more finished form in the forthcoming volume written in collaboration with Paul M. Sweezy than in earlier, piecemeal essays and chapters. It is only proper that an evaluation of this part of his work should wait until the eagerly expected volume by the two Pauls is published.

Mention must be made, however, of the concept of the economic surplus which Baran used as a unifying analytical device in studying monopoly capitalism in advanced industrialist societies, problems of underdevelopment, and the construction of a socialist society. While the inspiration for the concept as used by Baran stems from Marx, it is important to recognize that there is a very important difference between Baran's use of the "economic surplus" concept and Marx's theory of surplus value.

Marx sought in his theory of value and surplus-valuetaking into account the historical and analytical development (the inner logic à la Hegel) of these concepts-a unifying set of principles with which to explain the origins of capitalism and the nature of its growth, development, and decline. The theory was designed to explain, among others things, (1) the historical development of capital itself and its change from merchant to industrial capital; (2) the distribution of income and the struggles over the distribution of income; (3) the nature and limits of the economic and political struggle over the length of the working day and conditions of work in the factory; (4) the rise of productivity and the advance of technology; and (5) the drive to accumulate capital, from its historical origin in primary accumulation to its position as the controlling force in the expansion and contraction of capitalist economies. The accomplishment of all this required a complex analytical construction and a technical consistency. For Marx not only attempted to show how the exchange process continuously recreates, via value-exchange and surplus value, the social compulsions of capitalist relations; he also attempted to explain how 
the capitalist economy, working through the market, reproduces itself and at the same time creates the conditions for the expansion of internal markets and the accumulation of capital.

Now the complex, technical concept of surplus value has at its foundation a much simpler idea: an economy, with a given technique of production, can continue operating at a given level only if it can provide enough goods to keep the workers alive and working and to replace the tools used in production; an economy can grow only if it can produce an excess-a surplus-over the amount needed to replace the worker and his tools. The surplus-its size and its method of use-determines the growth potential of an economy. Marx's theory was hammered out to explain how this surplus is created and used in the historical development and operation of capitalism. Baran, on the other hand, used only the "simple" concept of the economic surplus (enriched by Marx's study and theory), and he used it as a more general device, to some extent for pedagogic purposes. For Baran does not examine the actual surplus in all its phases of development; in this respect, he took Marx's work for granted and focused his own attention primarily on what he called the potential surplus. The latter is an active, operative concept: it leads to an understanding of the waste, inefficiency, and unfulfilled possibilities of monopoly capitalism; it also leads to the recognition that the real needs of underdeveloped societies for substantial progress can be met only by a new social and economic organization that can mobilize the potential surplus and put it to use in the interests of the people.

Baran's diagnosis is rich in detail and encompasses subtle variations in the problems of different parts of the globe. We must content ourselves with a bare outline of his argument.

Baran argues that the root causes of the economic and social backwardness in our age are to be found in imperialism. Imperialism operated differently in India, Africa, Latin Ameri$\mathrm{ca}$, and other colonial areas, conditioned by variations in historical circumstances in the mother country and in the colonial areas themselves. But the forces of imperialism, whatever specific forms they may take, have had a similar effect in the dominated countries: to harden and strengthen the sway of merchant capitalism in the colonial nations and to slow down, if not en- 
tirely prevent, the transformation of this merchant capitalism into industrial capitalism.

Imperialist power achieved a stable and servile society by, on the one hand, protecting and strengthening a feudal-mercantile order, and on the other hand, preventing the development of a revolutionary middle-class by economically strangling indigenous industrial capitalism. The resulting social systems in these areas are under the control of a political and social coalition of wealthy compradors, monopolists granted special favor by the state, and large landowners-all dedicated to the defense of the existing economic structure and its established ties to the metropolitan center.

The net effect of this type of social and economic structure is a slow and lop-sided growth, partly stimulated by investments and technical know-how from the Western world and by charity. The slow growth is usually dissipated by rapid population growth, corruption in government, and the squandering of resources by the ruling oligarchy. The causes of the slow growth are definitely not those identified by the academic economists: shortage of capital, lack of entrepreneurial talent, or overpopulation. These are symptoms, not causes, and they reflect the existing social and economic organization.

A substantive change from slow growth-and the hunger, disease, and misery associated with it-can only be accomplished by major and far-reaching structural changes. Large investments in construction and machinery, long-term planning, and overcoming tradition-bound patterns of work and thought are needed for such nations to shift into high gear and achieve a large and continuous enough increase in output and productive capacity to outstrip population growth and bring about a meaningful rise in living conditions.

But this means a sweeping reorganization of society, an all-out mobilization of creative potentials, and appropriating and controlling the economic surplus now flowing into the pockets of the wealthy.

A necessary condition for effecting such a sweeping reorganization of society is political national independence-freedom from the direct control of a foreign state or the indirect, more "democratic," control of a strong imperialist power. Given 
political independence, according to Baran, some of the obstacles to economic and social development can be overcome. But it does not eliminate either the oppression and exploitation of the peasantry by the landed aristocracy or the strangulation of industrial development by monopoly business.

Furthermore, imperialism as an effective system of control is not automatically removed by political independence. The economic structure that was built as part of the market system and the investment pattern of the metropolitan center lives on. And with it economic dependence lives on. Meanwhile, the tenuous coalitions of socially heterogeneous groups that rule the newly independent nations are faced with processes of disintegration, speeded up by an intensification of internal class conflict resulting from rising popular aspirations to social as well as national liberation.

The only rational solution of the problems of backwardness and economic dependence is socialist economic planning. Requiring a change in the location of class power, a removal of control over economic resources from the partners of imperialist powers, it offers the medium for mobilizing an economic surplus far in excess of the "normal" surplus and an opportunity for effective utilization of the surplus for rapid growth of productive powers.

Significant economic developments, whether under socialist economic planning or as a breakthrough in a capitalist framework, are inimical to the interests of the dominant classes in the advanced capitalist nations. The task of imperialism in our time is therefore to slow down and control economic dedevelopment. In place of the white man's burden and the introduction of "civilization," economic development guided by the metropolis becomes the rationalization of today's imperialism. The claws behind this liberalism appear when a country takes off under its own steam toward economic development, sometimes only when the first baby-steps are taken.

Since Baran's book was published, his thesis on the opposition of imperialism to independent economic development has been all too well substantiated in one way or another by actions of the United States and other imperialist powers in 
Guatemala, Cuba, British Guiana, Brazil, Vietnam, Malaysia, and the Congo.

To get the full significance of Baran's contribution, the entire book has to be read and studied. There we can learn much from the spirit as well as from the substance, and we can hardly fail to be deeply moved by its eloquent concluding paragraph:

To contribute to the emergence of a society in which development will supplant stagnation, in which growth will take the place of decay, and in which culture will put an end to barbarism is the noblest, and, indeed, the only true function of intellectual endeavor. The need for the triumph of reason over myth, for the victory of life over death cannot be proved by means of logical inference. As a great physicist [Max Planck] once said, "Logic alone is incapable of carrying anyone beyond the realm of his own perception; it cannot even compel him to recognize the existence of his fellow men." This need must rest on the proposition that humanity's claim to life, to development, to happiness requires no justification. With this proposition it stands and falls. This proposition is, however, its sole unprovable and irrefutable premise. 